\title{
Innovation, Tourism Demand and Inflation: Evidence from 14 European Countries
}

\author{
Enn-Lun Yong
}

\begin{abstract}
The purpose of the paper is to investigate how inflation have altered the contribution of innovation to the tourism demand to the European countries during the last few decades. A hypothesis is proposed to prove that innovation of highly innovative countries in promoting their tourism industry. In addition, it is to assess how this relationship has been altered by the costs of inflation in the countries. Based on the recent Global Innovation Index (GII), 14 European countries are chosen as sample, while these countries have been incurring the inflation over the sample period, 1988-2010. A fixed-effect panel data framework is estimated with the Feasible Generalized Least Squares method with bias correction. The study utilizes innovation indicator to access the impact of costs on innovation to the tourism sector. To ensure robustness of estimation, the study focuses on the sensitivity of estimation with respects to the time lag by estimating the models with sufficient number of time lag, while also ensuring the sufficient degree of freedom for the estimation. The result supports the hypothesis that the countries have increasingly stronger position of innovation to the tourism industry and this benefit is not altered by the inflation pressure occurred in the countries.
\end{abstract}

Index Terms-Costs, inflation, innovation, tourism demand.

\section{INTRODUCTION}

Generally, the high cost of travelling in a country which incurs inflation will reduce the amount of both international and local tourists, including both business and leisure travellers. Moreover, this high cost of travelling may also reduce the attractiveness of other factors to the tourists, such as the innovative products from the tourism sector. In order to know this effect, we need a well-developed conceptualization of the tourism sector as a service industry in order to identify the potential effect of the inflation costs. A study explains that the service industry has evolutional nature and it comes from a dynamic aggregation due to the interaction of various economic actors, resources, and contexts [1]. While the service industry is typical to innovation, there is hardly evidence in terms of how innovation attractiveness to consumers to be distorted by the inflation costs.

The objective of this paper is to investigate the extent to which tourism demand for the European countries in response to innovation in the context of increasing inflation over two decades from the late 1980s to the early 2010s. By applying panel data method in testing the relationship from 14 European countries, the results indicate that the inflation effect to tourism demand to 14 European countries has been

Manuscript received April 10, 2013; revised June 17, 2013.

Enn-Lun Yong is with the School of Science and Technology, Universiti Malaysia, Kota Kinabalu, Sabah, CO 88400 Malaysia (e-mail: ennlunyong@gmail.com). increasing. Given this costly situation, innovation is found to have significant relationship with the tourism demand, while the magnitude of relationship gradually becomes larger as the time lag decreases. The result, therefore, is that the European countries have sustainable innovation environment for their tourism sector and are not vulnerable to the high cost pressure due to the inflation phenomenon.

The following sections consist of the reviews of innovation and inflation costs, the mathematical explanation of the hypothesis proposed in this paper and the results and discussion.

\section{INNOVATION AND INFLATION COSTS}

Innovation is widely agreed about its essential role in developing the tourism sector and this has triggered burgeon empirical studies with a diversity of methodology [2]. On one hand, one concern is in the search for the kinds of incentive of innovation for enterprises and organizations, such as the consumer driven process. For instance, the consumption of tourists is found important because it reflects to the attractiveness of tourism products. Moreover, the selective nature of cultural tourists is found can shape the production process of tourism products [3]. On the other hand, many other studies have explained what innovation can do in enhancing the operation of tourism business. For instance, innovation is found to be a form of internationalization in terms of tourism operations [4]. Nevertheless, enhancing innovation might also increase the costs in the form of distorted productivity as what has been proved theoretically, as a result of increasing complexity in the production process [5]. Nonetheless, there is no evidence of how the adoption of innovation in the tourism sector will be distorted due to inflation in a country or a group of countries in one geographical area.

There is no direct evidence of the impact of inflation on innovation in the tourism industry, but the search for the impact of oil prices on the tourism industry has contributed the relevant insights. Rising oil price is formally proved to have significant effect on inflation in causality testing in the sense that the occurrence of inflation was later than the increase of oil price in the OECD countries [6]. The European countries have been focused for this issue due to their rich inflation experience as a result of the shock of oil prices since the 1970s. For example, oil price is found can lead to hyperinflation in the context of flexible wage, interest rate, profit and rent to price adjustment in the case of Turkey [7], while the effect on inflation can be permanent in the European countries [8]. The United Kingdom, for instance, is found to have inflation effect spreading to real economy 
through altering the interest rate, while France and Italy incurred an offset situation due to the adoption of easing monetary policy [9]. However, the inflationary effect due to this oil price shock is found to be more serious in the case of Spain compared to other euro area, such as the impact on wage [10]. Although the oil price pass-through inflation effect is observed, there is also evidence that shows the improvement in the situation where the inflation pressure declines when oil price increases, which is found to be a result of the improvement in the monetary policy, higher degree of trade openness and domestic currency appreciation [11]. Notwithstanding with this findings about inflation in Europe that due to the oil price shock, evidence of the impact on tourism sector is hardly available. The early attention to this issue was observed in the late 1970s, in one international symposium tagged as 'tourism and the next decades' [12]. On the one hand, high oil-price induced inflation may be considered to have destructive effect to tourism demand in a country in the sense that tourism is a discretionary and oil-intensive activity, which can be vulnerable to oil price change. On the other hand, there may also be inflation pressure that is beneficial to tourism demand to a country due to the reason such high oil price also raises the income of the oil producing countries [13]. Moreover, an investigation in some European Mediterranean countries shows evidence of oil price shock with lag effects on tourism contribution to the economies in terms of income and growth [14]. In short, innovation is an extremely important dimension for the tourism sector as observed in the European countries, while the relationship is empirical answer when the inflation effects are taken into consideration.

\section{THE STUdy AND METhodology}

In order to measure the impacts of innovation on the tourism demand to the countries as in other macroeconomic investigations [15]-[18], the patent application indicator is utilized as approximation to innovation. The study uses panel framework in order to investigate the relationship and in order to enhance the feasibility in terms of applying the econometric method with some heteroscedasticity effects across the countries, the Feasible Generalized Least Squares (FGLS) method with bias-correction is applied. This method is proved to have higher power of test compared to the Ordinary Least Squares method [19]. Due to reason that the inflation pressure also involves time lag effect and meanwhile in order to ensure robustness in the estimations [20], the study tests for the time lag effect up to 10-year long.

Due to the important role of innovation to economic development, as explained by Schumpeter [21] which is also supported by studies about innovation in the service industry [22]-[24], the null hypothesis underlying the study is that innovation has significant relationship with the tourism demand to a group of European countries, regardless of the inflation pressure.

Equations (1) to (5) are the mathematical model that explains the mechanism of interaction of three variables, including inflation, innovation, and the tourism demand.

$$
V=f(P, N)
$$

$$
\begin{gathered}
\frac{d V}{d N}=f(\theta, P) \\
\frac{d V}{d N}=\frac{\theta}{P} \\
\int d V=\int \frac{\theta}{P} d N \\
V=\frac{\theta N}{P}+C
\end{gathered}
$$

where

$V=$ tourism demand measured with visitor export as ratio to total export of goods and services, $P=$ inflation costs measured with consumer price index, $N=$ innovation measured with total patent application by both residents and non-residents, $\theta=$ indication of country specific factors, and $C=$ a constant term.

Equations (1) to (5) show the possible relationship between tourism demand $(V)$ and innovation $(N)$ when the inflation costs $(P)$ are also taken into consideration. The change of tourism demand with respect to the change of innovation is specified as a function of the inflation costs $(P)$ and a country specific factor $(\theta)$. The change is reciprocal to the inflation costs as a ratio of the country specific factor $(\theta)$ to the inflation costs $(P)$. In essence, equation (5) indicates that the tourism demand $(V)$ can be influenced by the innovation $(N)$ and the country specific factor $(\theta)$ weighted by the inflation $\operatorname{costs}(P)$. As such, it means that the effect of innovation on tourism demand can be outweighed by the effect of inflation costs. The continuous transformation is shown in (6) to (8), which specified in logarithm form.

$$
\begin{gathered}
\log V=\log \left(\frac{\theta N}{P}\right)+\log C \\
\log V=\log \theta+\log N-\log P+\log C \\
\log V_{t, i}=\alpha_{t, i}+\beta_{1} \log N_{t, i}-\beta_{2} \log P_{t, i}+\varepsilon_{t, i}
\end{gathered}
$$

where

$\alpha=\mathrm{A}$ parameter that indicates $\log \theta+\log C, i=$ cross-section indication, and $t=$ time period indication.

The purpose of logarithm transformation in the equations is to obtain a linear approximation of the model so that estimation can be simplified. Furthermore, the logarithm model can easily make the pattern of relationship visible in terms of positive and negative relationship. For instance, the innovation coefficient $\left(\beta_{1}\right)$ in $(8)$ is pre-determined to be positively related to the tourism demand $(V)$. In contrast, the coefficient of inflation costs $\left(\beta_{2}\right)$ is pre-determined to be negatively related to the tourism demand $(V)$. The constant term $(\alpha)$ is the combination of $(\log \theta)$ and $(\log C)$ in which it also shows the existence of country specific effect on the tourism demand. 
In order to obtain the empirical evidence, several countries are chosen according to the status of tourism development and innovation over the past decades. In terms of tourism circumstances, the study focuses on the cost of travelling and the heritage aspect of tourism in the countries as its importance can be seen to be crucial attraction factors for tourists, while also different across countries. In terms of innovation, the countries are chosen according to the latest information from the Global Innovation Index (GII) 2012. As a result of selection, 14 countries are chosen from among the European countries which have highest innovation ranking in the GII as well as well-equipped with rich tourism heritage sites. The sample consists of Switzerland, Sweden, Finland, United Kingdom, Netherlands, Denmark, Ireland, Luxembourg, Norway, Germany, Iceland, Belgium, Austria and France. In a nutshell, the sample are some highly innovative countries which also rich in tourism attraction, while there is upward trend in the inflation costs over the pass decades, as illustrated in Fig. 1.



Fig. 1. The changing price level over the $1988-2010$ period in 14 European countries, including Switzerland, Sweden, Finland, United Kingdom, Netherlands, Denmark, Ireland, Luxembourg, Norway, Germany, Iceland, Belgium, Austria and France.

The statistical measurement for the tourism demand variable $(V)$ is the total expenditure by international tourists in both business and leisure trips, including transportation spending. The indicator is the share of visitor export of total export of all goods and services for the 1988-2010 periods, obtained from the World Travel and Tourism Council (WTTC). The cost of traveling $(P)$ is approximated by the price index (based year in 2005) of each of the countries for the same period. In order to measure innovation of the countries, patent indicator of the number of patent application by both residents and non-residents is used as proxy. Both price index and patent indicator are obtained from the World Development Indicator (WDI) of the World Bank.

For the purpose of estimation, the study considers the advantages of fixed effect panel data approach compared to both time series and cross-sectional approaches. The panel data model specification takes both time series and cross-section units into account, while it also reduces the problems such as multicollinearity and heteroscedasticity that usually prevail in the two former approaches. Furthermore, the study intends to increase the feasibility of the estimation that involves heteroscedasiticity effect by using the Feasible Generalized Least Squares (FGLS) by assigning weight calculated with this method and correcting cross-sectional heteroscedasticity and contemporaneous correlation by using the Seemingly Uncorrelated Regression (SUR) correction method.

\section{RESUlT AND DisCUSSION}

TABLE I: ESTIMATION RESULT

\begin{tabular}{|c|c|c|c|}
\hline \multicolumn{4}{|c|}{ Dependent variable: Visitor export } \\
\hline $\begin{array}{c}\text { Lag } \\
\text { Length }\end{array}$ & $\begin{array}{c}\text { Independent } \\
\text { variable: } \\
\text { Price } \\
\text { Index }\end{array}$ & $\begin{array}{c}\text { Independent } \\
\text { variable: } \\
\text { Patent } \\
\text { Index }\end{array}$ & $\begin{array}{c}\text { Normality } \\
\text { Test }\end{array}$ \\
\hline 0 & $\begin{array}{c}-0.6106 * * * \\
(0.0793)\end{array}$ & $\begin{array}{c}0.1846 * * * \\
(0.0293)\end{array}$ & $\begin{array}{c}3.9706 \\
{[0.1327]}\end{array}$ \\
\hline 1 & $\begin{array}{c}-0.6408 * * * \\
(0.0865)\end{array}$ & $\begin{array}{c}0.1795 * * * \\
(0.0266)\end{array}$ & $\begin{array}{c}3.0597 \\
{[0.2166]}\end{array}$ \\
\hline 2 & $\begin{array}{c}-0.7499 * * * \\
(0.0821)\end{array}$ & $\begin{array}{c}0.1624 * * * \\
(0.0228)\end{array}$ & $\begin{array}{c}1.7242 \\
{[0.4223]}\end{array}$ \\
\hline 3 & $\begin{array}{c}-0.8379 * * * \\
(0.0819)\end{array}$ & $\begin{array}{c}0.1443 * * * \\
(0.0224)\end{array}$ & $\begin{array}{c}0.6975 \\
{[0.7056]}\end{array}$ \\
\hline 4 & $\begin{array}{c}-0.8862 * * * \\
(0.0791)\end{array}$ & $\begin{array}{c}0.1338 * * * \\
(0.0211)\end{array}$ & $\begin{array}{c}1.7615 \\
{[0.4145]}\end{array}$ \\
\hline 5 & $\begin{array}{c}-0.8883 * * * \\
(0.0799)\end{array}$ & $\begin{array}{c}0.1181 * * * \\
(0.0214)\end{array}$ & $\begin{array}{c}0.9353 \\
{[0.6265]}\end{array}$ \\
\hline 6 & $\begin{array}{c}-0.9105 * * * \\
(0.0784)\end{array}$ & $\begin{array}{c}0.1239 * * * \\
(0.0224)\end{array}$ & $\begin{array}{c}0.1914 \\
{[0.9087]}\end{array}$ \\
\hline 7 & $\begin{array}{c}-0.8912 * * * \\
(0.0822)\end{array}$ & $\begin{array}{c}0.0994 * * * \\
(0.0225)\end{array}$ & $\begin{array}{c}0.3099 \\
{[0.8564]}\end{array}$ \\
\hline 8 & $\begin{array}{c}-0.8530 * * * \\
(0.0852)\end{array}$ & $\begin{array}{c}0.0813 * * * \\
(0.0250)\end{array}$ & $\begin{array}{c}2.4774 \\
{[0.2898]}\end{array}$ \\
\hline 9 & $\begin{array}{c}-0.8333 * * * \\
(0.0787)\end{array}$ & $\begin{array}{c}0.0647 * * * \\
(0.0248)\end{array}$ & $\begin{array}{l}5.9135^{*} \\
{[0.0513]}\end{array}$ \\
\hline 10 & $\begin{array}{c}-0.8570 * * * \\
(0.0632)\end{array}$ & $\begin{array}{c}0.0311 \\
(0.0240)\end{array}$ & $\begin{array}{c}3.8324 \\
{[0.1472]}\end{array}$ \\
\hline
\end{tabular}

$\overline{\text { Note: The constant values are ranged from } 3 \text { to } 5 . *, * \text { and } * * * \text { indicate } 10 \%}$, $5 \%, 1 \%$ significance level, respectively. The values in the ( ) are standard error of the coefficient and the values in [ ] are the probability values for the normality Jacque-Bera statistics. All variables are in logarithm form.

To test for the null hypothesis that innovation has positively significant relationship with tourism demand to the list of European countries, equation (8) is estimated and the result is presented in Table I. It shows the estimation of both independent variables, the price index and patent index with time lag extended up to ten years. The estimations are checked with the normality test using the Jarque-Bera statistics at $5 \%$ critical value in order to ensure the goodness-of-fit of the models before the hypothesis testing. The estimation of each model has insignificant statistic in the normality test, which means the estimated residuals have normal-distribution in each model. The price index coefficients are estimated to between 0.61 with small lag length and 0.85 with large lag length. This implies that the high costs of travelling have reduced tourism demand for the European countries, while this effect has been persistent over the two decades. Fig. 2 depicts the pattern of price index coefficients throughout the lags up to 10 years. The result seems to be consistent to the increasing trend in the price index over the 1988-2010 periods, which reflects that consumers continuously expect prices to increase in the 
countries and adjust their demand for tourism accordingly.

Upon controlling for the inflation costs, the examination on the innovation is done with the check on the relationship signs as well as the magnitude of the patent index coefficients throughout the lags until 10 years long. The first estimate of patent index appears to be about 0.18 , which implies that the effect is smaller than the inflation cost effect in the countries. More importantly, these positive values of estimation gradually decline as the time lag increases until the ninth lag, while remain to be positive and significant throughout the lagging period. Fig. 3 shows the plot of these patent index coefficients throughout the lags of 10 years. The significantly sustainable development of innovation in the European countries for decades provides indication to this declining pattern. It has benefited the tourism sector for the European countries very much even in the context of increasing inflation costs. In particular, this innovation becomes one form of attractiveness to tourists, which can partially offset the effect of the inflation costs. Furthermore, this is supported by the finding across the European regions in which innovation within a region is found to have $80 \%$ to $90 \%$ innovative outputs, while there is also spillover effect to other regions even it is only $2 \%$ to $3 \%$ [25]. Nevertheless, the innovation benefit to the tourism sector is not from the sector itself, instead it is the innovation benefit from the combination of different sectors. This is explained in the finding that when there is diversified innovation from a complementary set of industries from a common science base, innovation activities tent to be higher [26].



Fig. 2. Price index coefficients with lagged length

In a nutshell, the hypothesis should not be rejected based on the testing results in the sense that innovation has significant contribution to the tourism demand although the inflation costs have been increasing in the same period. Furthermore, innovation can be a type of compensation to the high costs of travelling to tourists by providing new experience to tourists with a variety of tourism related products and amenities such as restaurants, visiting sites, technology and entertainment, and infrastructure.

For robustness of estimation, the process of estimation is repeated with different coefficient covariance estimations in the GLS estimation process, including White cross-section, White diagonal, cross-section weight and the Seemingly Uncorrelated Regression (SUR) weight. Furthermore, the estimation on the estimates of both price index and patent index has been extended by involving up to 10 lags in order to check for the sensitivity of the result in terms of time dimension. The results for the changes in the price index coefficient and the patent index coefficient are consistent among the covariance bias-correction methods. Therefore, it ensures that the initial result from the Seemingly Uncorrelated Regression (SUR) estimation as shown in Table $\mathrm{I}$ is robust.

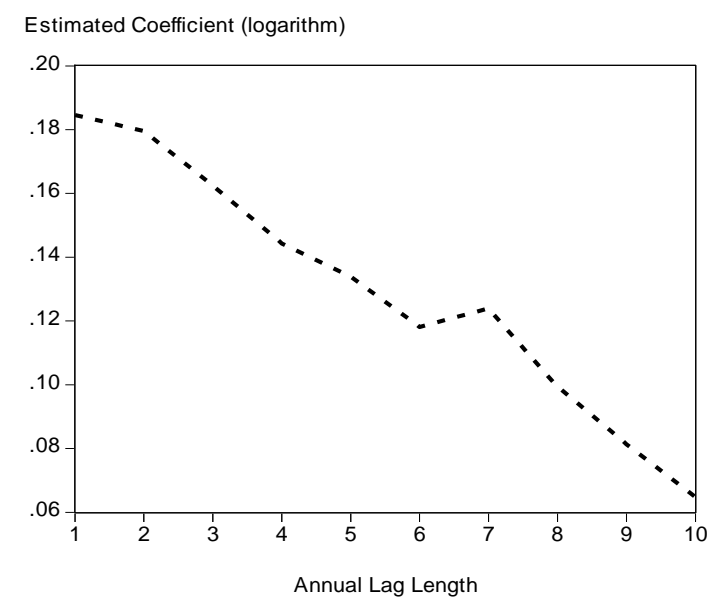

Fig. 3. Patent index coefficients with lagged length.

\section{CONCLUSION}

With sustainable development of innovation in the European countries, it can offset the high cost due to inflation and therefore improve the demand for the tourism products. This paper proposes the hypothesis in terms of tourism industry in some highly innovative countries which are experiencing upswing costs in their economy. To prove this hypothesis, 14 European countries are identified as sample for the study, including Switzerland, Sweden, Finland, United Kingdom, Netherlands, Denmark, Ireland, Luxembourg, Norway, Germany, Iceland, Belgium, Austria and France. The study utilizes the total patent application index as proxy for innovation. The inflation costs are approximated by the price index and the tourism demand is measured by the share of visitor export out of the total exports of goods and services. The methodology involves the use of fixed effect panel data model estimated by the Feasible Generalized Least Squares (FGLS) in order to obtain accurate estimation by assigning FGLS-weights to each cross-section unit and by correcting the bias in the coefficient covariance with the Seemingly Uncorrelated Regression (SUR) method and other alternative methods. The results indicate significantly positive impact of innovation on the tourism demand to the European countries. The hypothesis is true in the sense that the innovation effect involves sustainable benefit to the tourism sector in the countries over a span of nearly one decade, although inflation costs have longer, larger and negative effect to the tourism sector.

\section{REFERENCES}

[1] B. Chae, "An evolutionary framework for service innovation: insight of complexity theory for service science," Int. J. Prod. Econ., vol. 135, no. 2, pp. 813-822, Feb. 2012.

[2] A.-M. Hjalager, "A review of innovation research in tourism," Tourism Manage, vol. 31, no. 1, pp. 1-12, Feb. 2010. 
[3] G. Richards, "Production and consumption of European cultural tourism." Ann. Tourism Res., vol. 23, no. 2, pp. 261-283, 1996.

[4] A. M. William and G. Shaw, "Internationalization and innovation in tourism," Ann. Tourism Res., vol. 1, no. 38, pp. 27-51, Jan. 2011.

[5] P. Waelbroeck, "Innovations, production complexity and the optimality of R \& D," Econ. Lett., vol. 2, no. 79, pp. 277-282, May 2003.

[6] I. A. Moosa, "Can OPEC cause inflation and recession?" Energ. Policy., vol. 21, no. 11, pp. 1145-1154. Nov. 1993.

[7] H. Berument and H. Taşc i, "Inflationary effect of crude oil prices in Turkey," Phys. A. Stat. Mech and Appl., vol. 316, no. 1-4, pp. 568-580, Dec. 2002.

[8] J. Cuñado and F. P. D. Gracia, "Do oil price shocks matter? Evidence for some European countries," Energ. Econ., vol. 25, no. 2, pp 137-154, Mar. 2003.

[9] A. Cologni and M. Manera, "Oil prices, inflation and interest rates ion a structural cointegrated VAR model for the G-7 countries," Energ. Econ., vol. 30, no. 3, pp. 856-888, May 2008.

[10] L. J. Ávarez, S. Hurtado, I. Sánchez, and C. Thomas, "The impact of oil price changes on Spanish and euro area consumer price inflation," Econ. Model, vol.28, no. 1-2, pp. 422-431, Jan.-Mar. 2011.

[11] S.-S. Chen, "Oil price pass-through into inflation," Energ. Econ., vol. 31, no. 1, pp. 126-133, Jan. 2009.

[12] A. F. Burkart, "Inflation and energy - will they halt tourism growth? Tourism and the next decade," in Proc. An International Symposium Held at the George Washington University, Washington DC, 11-15 March 1979, Future, vol. 11, no. 3, pp. 258-259, June 1979.

[13] S. Becken and J. Lennox, "Implications of a long-term increase in oil prices for tourism," Tourism Manage, vol. 33, no. 1, pp. 133-142, Feb. 2012.

[14] L. Chatziantoniou, G. Fillis, B. Eeckels, and A. Apostolakis, "Oil prices, tourism income and economic growth: a structural VAR approach for European Mediterranean countries," Tourism Manage, vol. 36, pp. 331-342, June 2013.

[15] P. LeBel, "The role of creative innovation in economic growth: some international comparisons," J. Asian Econ., vol. 4, no. 19, pp. 334-347, Aug. 2008.

[16] A. B. Reis and D. A. Traca, "Spillovers and the competitive pressure for long-run innovation," Eur. Econ. Rev., vol. 52, no. 4, pp. 589-610, May 2008.

[17] I. S. Akc omak and B. ter Weel, "Social capital, innovation and growth: evidence from Europe," Eur. Econ. Rev., vol. 53, no. 5, pp. 544-567, July 2009.
[18] C. Lorenczik and M. Newiak, "Imitation and innovation driven development under imperfect intellectual property rights," Eur. Econ. Rev., vol. 56, no. 7, pp. 1361-1375, Oct. 2012.

[19] C. B. Hansen, "Generalized least squares inference in panel and multilevel models with serial correlation and fixed effects," $J$. Econometrics., vol. 140, no. 2, pp. 670-694, Oct. 2007.

[20] M.-H. Wu and Y.-S. Ni, "The effects of oil prices on inflation, interest rates and money," Energ., vol. 36, no. 7, pp. 4158-4164, July 2011.

[21] J. A. Schumpeter, The Theory of Economic Development; Oxford: Oxford University Press, 1911

[22] I. Drejer, "Identiying innovation in surveys of services: a Schumpeterian perspective," Res. Policy, vol. 33, no. 3, Apr. 2004.

[23] G. Bertocco, "Finance and development: is Schumpeter's analysis still relevant?" J. Bank. Financ., vol. 32, no. 6, June 2008.

[24] M. Bittencourt, "Financial development and economic growth in Latin America: is Schumpeter right?" J. Policy Model, vol. 34, no. 3, May-June 2012

[25] L. Bottazzi and G. Peri, "Innovation and spillovers in regions: evidence from European patent data," Eur. Econ. Rev., vol. 47, no. 4, pp. 687-710, Aug. 2003.

[26] M. P. Feldman and D. B. Audretsch, "Innovation in cities: science-based diversity, specialization and localized competition," Eur. Econ. Rev., vol. 43, no. 2, pp. 409-429, Feb. 1999.

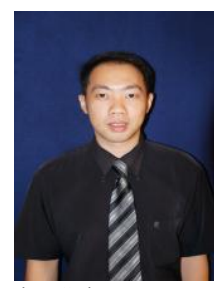

Yong Enn Lun comes from the Sabah state of Malaysia and was born in 1983. Yong has attained the Bachelor of Economics with Honours in financial economics in 2008 from Universiti Malaysia Sabah, a state university located in the Sabah state of East Malaysia. Yong has also attained the Master of Economics in 2010 from Universiti Kebangsaan Malaysia, the national university of Malaysia located in the Selangor state of West Malaysia. Yong's major field of study in the master degree is econometrics. He is a lecturer in the School of Science and Technology of University Malaysia Sabah since August 2011. He involves in the teaching of mostly economic related subjects, including microeconomics, macroeconomics and econometrics. His current research interest is the study that focuses on the insight related to role of innovation in economic development, with the application of econometric methods. Particularly, he is interested in searching for the best integration of economic theory, mathematical economics, and econometric methods that lead to the most reliable and valid conclusion of the topic under investigation. 